\title{
INICIAÇÃO CIENTÍFICA: POSSIBILIDADES E LIMITES À INSTAURAÇÃO DE UM CÍRCULO VIRTUOSO
}

\begin{tabular}{c}
\hline SCIENTIFIC INITIATION: OPPORTUNITIES AND LIMITS \\
FOR THE CREATION OF A VIRTUOUS CIRCLE \\
\hline INICIACIÓN CIENTÍFICA: POSIBILIDADES Y LÍMITES \\
A LA INSTAURACIÓN DE UN CÍRCULO VIRTUOSO
\end{tabular}

Adriano de Oliveira ${ }^{i}$

RESUMO

Lucídio Bianchetti ${ }^{\text {ii }}$

Neste artigo, de caráter teórico-empírico, resultante de uma pesquisa de doutorado, refletimos sobre aspectos relacionados à extensão da Iniciação Científica (IC) à Educação Básica (EB), com a implementação da Iniciação Científica Júnior (ICJ), a partir do ano de 2003. Com características que se aproximam e outras se distanciam da consolidada IC na Graduação, a ICJ conta com poucos dados e pesquisas. Constatamos que se objetiva, por meio da política de IC e ICJ, aproximar a Pós-graduação, a Graduação e a EB, processo que tem possibilitando que muitos bolsistas incorporem certos habitus específicos do campo acadêmico. Em termos antropológicos e educacionais, este processo pode ser caracterizado como um "ritual de iniciação ou passagem", aqui entendido como rito de formação.

PAlaVRaS-ChaVE: Iniciação científica. Processo de orientação. Educação básica

\section{ABSTRACT}

This article of a theoretical-empirical scope and the result of a doctoral study, reflects on aspects related to the extension of the Scientific Initiation for Basic Education internship program, with the implementation of the Junior Scientific Initiation, since 2003. With some characteristics that approximate and others that are distant from the Scientific Initiation program already consolidated at the undergraduate level, there are few studies and little data about the junior program. We found that by means of the IC and ICJ policy, an effort was made to approximate graduate, undergraduate programs to basic education, which has allowed many grantees to incorporate certain specific habitus from the academic field. In anthropological and educational terms, this process can be characterized as a "ritual of initiation or passage", and understood here as a rite of formation.

KEYWORDS: Scientific initiation. Orientation process. Basic education.

\section{RESUMEN}

En este artículo, de carácter teórico-empírico, resultante de una investigación de doctorado, reflexionamos sobre aspectos relacionados con la extensión de la Iniciación Científica a la Educación Básica, con la implementación de la Iniciación Científica Júnior, a partir del año de 2003. Con características que se acercan y otras que se alejan de la consolidada IC en el Grado, la ICJ cuenta con pocos datos e investigaciones. Constatamos que se objetiva, por medio de la política de IC e ICJ, aproximar Posgrado, Grado y EB, proceso que ha posibilitado que muchos becarios incorporen algunos habitus específicos del campo académico. En términos antropológicos y educacionales, este proceso puede ser caracterizado como un "rito de iniciación o de paso", aquí entendido como rito de formación.

PALABRAS ClaVE: Iniciación científica. Proceso de orientación. Educación básica. 


\section{INTRODUÇÃo}

A Iniciação Científica (IC) na Graduação conta com uma história cujos primeiros passos remontam, formalmente, à criação do Conselho Nacional de Desenvolvimento Científico e Tecnológico (CNPq) em 1951. Nesse processo, no final da década de 1980 o CNPq alça a IC à condição de "Programa" com a criação do "Programa Institucional de Bolsas de Iniciação Científica" (PIBIC) (PIRES, 2008). Na Educação Básica (EB) contudo, sua inclusão é mais recente. Neste texto, sem deixar de mencionar brevemente alguns dos desafios sociais, culturais, pedagógicos e políticos à implementação e à materialização da Iniciação Científica (IC), daremos atenção particular, à gênese da concessão de bolsas de Iniciação Científica Junior (ICJ) pelo CNPq, a partir do ano de 2003 e a alguns dados, bem como aspectos envolvidos e decorrentes dessa extensão da IC a alunos da EB.

Este texto resulta de parte de uma pesquisa desenvolvida no âmbito do doutorado em educação em uma universidade da região Sul do Brasil. O que segue resulta de nossas reflexões, da revisão de literatura e fundamentação sobre a temática, bem como de pesquisa empírica. Inicialmente explicitamos que a $\mathrm{ICJ}^{\mathrm{iii}}$ para os estudantes que passam a integrar-se no Programa, aproxima-se ou assemelha-se a um ritual de iniciação ou passagem. Em seguida apontamos alguns questionamentos que perpassam essa temática e que exigem maior aprofundamento teórico-metodológico como, por exemplo, a relação orientador-orientando. No próximo item evidenciamos o quanto a IC é uma política recente no Brasil, embora haja vários estudos sistematizados em livros e artigos sobre a temática principalmente na Graduação. Logo em seguida: "Da inexistência à condição de "prima rica" ressaltamos que com a implantação da Pós-graduação (PG) stricto sensu no Brasil nos anos de 1960 a prioridade era a formação para a docência na Educação Superior (ES). Porém com a expansão da PG a formação de pesquisadores, a partir de meados da década de 1990, impõese como nova prioridade e com isto a IC ganha um impulso e passa a ser o espaço de iniciação à pesquisa, originalmente para graduandos e, em período mais recente, expandindose também a discentes da EB. Por fim, destacamos alguns desafios e/ou limites da política de IC no Brasil.

Em termos empíricos foram entrevistados 27 bolsistas, 11 orientadores, cinco coorientadores e três coordenadores da ICJ de uma Universidade Pública da região sul do Brasil. Neste artigo privilegiamos questões referentes aos alunos ${ }^{\mathrm{iv}}$, focalizando precipuamente aspectos teóricos - secundando os empíricos -, com a finalidade de introduzir uma discussão antropológico-educacional e refletir sobre questões que permeiam o ser/fazer da IC/J. 


\section{A INICIAÇÃo CIENTífICA COMO RITUAL. DA ANTROPOLOGIA À EDUCAÇÃo}

As leituras sobre a IC e os depoimentos dos nossos entrevistados permitem-nos partir da concepção de que a IC, pode ser compreendida ou inserida no espectro dos rituais, sejam de iniciação ou de passagem. Embora a nossa preocupação não se volte a questões antropológicas ou religiosas - terreno fértil de pesquisas e aprendizagens sobre os rituais e o papel plasmador de instituições e sociedades -, consideramos importante ressaltar algumas características desse processo de iniciação/passagem na perspectiva da universidade/escola, uma vez que isto nos possibilita tecer comentários, fazer algumas comparações e levantar questionamentos que consideramos pertinentes em relação à IC.

Uma simples 'consulta' ao 'dr. Google' - com a precariedade dos dados que contem - aponta para a existência de mais de 500 mil resultados relacionados à temática dos rituais de iniciação ou passagem. Esta cifra pode ser interpretada como uma indicação da importância do assunto no tocante à organização e ao funcionamento, seja de instituições ou sociedades arcaicas, seja modernas. Uma das principais características dos rituais é serem um divisor na vida de um indivíduo ou grupo, entre o 'não ser mais' e o 'ainda não ser'. Isto é, aqueles que são submetidos a rituais iniciáticos ou de passagem, ficam, por um período, em estágio de suspensão, em uma espécie de vazio, uma vez que precisam abrir mão do que eram e ainda não podem assumir de fato e de direito aquilo que pretendem ou são 'destinados' a ser. É uma fase de indeterminação, tematizada por antropólogos (VAN GENNEP, 1978) como uma condição de não pertencimento ou de limiar, caracterizada por três fases ritualísticas: de separação, de margem e de agregação. Nesse locus espácio-temporal, no entanto, dos iniciados, espera-se que assumam novas identidades, exerçam novos papéis. É o locus do exercício de abandonar o que eram/faziam e de antecipar, de iniciar-se no ser/fazer que pretendem após a 'passagem'. O depoimento do ex-bolsista de ICJ abaixo é revelador desse processo de iniciação.

Bom, era um jeito de entrar na universidade mais cedo. Como é dentro da universidade eu optei por conhecer mais. Assim, quando eu chegasse aqui eu já teria uma noção do que seria, como seria os professores, como seria as aulas (B10).

Os rituais foram/são típicos de cada povo, sociedade, época, praticados de maneiras diversas: profanos, religiosos, institucionais, festivos, violentos, escabrosos, simples, estranhos, complexos etc., como veremos adiante. Sua característica é a manutenção, o conservadorismo, a busca da garantia de continuidade e, principalmente, a previsibilidade, a segurança advinda da antecipação e da repetição. De acordo com Rodolpho (2004, p. 139), por meio dos rituais, busca-se garantir o status quo de forma consensuada. Contudo, 
uma solução de consenso é alcançada por todas as sociedades, quando a coletividade consegue - ou tenta - trazer os diversos acontecimentos diários que envolvem os indivíduos para dentro de uma esfera de controle e ordem, esfera esta coletiva, social. Os rituais, nesse sentido, concedem autoridade e legitimidade quando estruturam e organizam as posições de certas pessoas, os valores morais e as visões de mundo.

Deduz-se do acima explicitado que os rituais de iniciação/passagem não são simplesmente formas de diversão, meios de impedimento ou estratégias de matizes diversas visando introduzir, acomodar em um grupo aqueles que não pertenciam ou estavam 'excluídos'. Para além dessa concepção que pode povoar o senso comum, os rituais desempenham um papel pedagógico, de formação. A autora acima citada, referenciando-se em Andràs Zempléni, afirma que

o protótipo dos ritos de passagem são os ritos de iniciação: como os ritos de passagem, os ritos de iniciação marcam a transição de um status social para outro (morte e renascimento simbólicos). A iniciação é, portanto, a "forma sintética dos ritos de passagem, por meio dos quais ela opera". Mas a iniciação é mais do que simplesmente um rito de transição, ela é um rito de formação. Esta formação vai diferenciar os participantes ou o círculo dos neófitos dos "de fora", daqueles exatamente não-iniciados. Numerosas iniciações contam com ritos de inscrição nos corpos de marcas, signos visíveis da formação e transformação de nova identidade (escarificações, circuncisões, modificação do formato dos dentes, perfurações no nariz ou lábios etc.) (RODOLPHO, 2004, p. 144, grifo nosso).

Da abordagem antropológica a respeito desses rituais avançamos para algumas das suas implicações ou manifestações no campo da sociologia da educação. Nossa intenção não é fazer uma simples e linear transferência das explicações antropológicas às educacionais, mas chamar a atenção para aspectos que aproximam essas 'iniciações', alertando assim para determinados cuidados que é necessário ter com os sujeitos envolvidos na IC.

Reforçando, então, concebemos a IC no contexto dos rituais de iniciação ou passagem. Conforme visto sinteticamente acima, da antropologia nos vem a sistematização de conhecimentos a respeito do que é uma iniciação/passagem, para que serve, como é feita, o que ocorre com quem é submetido a esse processo, o que preside sua implementação etc. É neste sentido que a IC pode ser considerada um ritual, pois o discente não faz parte, é de fora e para ser incluído, para adquirir o habitus, precisa passar por situações materiais e simbólicas, que transformam o bolsista em alguém incluído, de dentro. Dessa forma, o ritual separa "aqueles que já passaram por ele daqueles que ainda não o fizeram e, assim, institui uma diferença duradoura entre os que foram e os que não foram afetados" (BOURDIEU, 1998, p. 97). 
Os que foram afetados, aqui no caso os bolsistas de IC, constituem uma identidade que é condição para serem admitidos, isto é, para ingressarem e manterem-se no campo acadêmico. O ser aceito aponta um reconhecimento do capital social e acadêmico do candidato a bolsista de IC, porém implica obrigações de seguir as regras explícitas e implícitas do campo. Há a imposição e a incorporação de "um dever de ser", de uma "segunda natureza" "sob a forma de habitus" (BOURDIEU, 1998, p. 100-103). O depoimento do bolsista abaixo demonstra essa dinâmica característica dos rituais de iniciação/passagem.

Eu queria participar do projeto, queria ter uma carga teórica maior, queria ter uma chance maior de ingressar numa universidade. Então eu quis e como tive sempre um bom aproveitamento na escola, sempre fui bem na escola eles me escolheram por eu ter essa facilidade, essa carga maior de responsabilidade (B2).

Um campo é criado para produzir, reproduzir as disposições, posições e habitus que permitem a manutenção das relações características desse ambiente. Por isso, há no campo acadêmico uma "crença que o sustenta" um "jogo de linguagem que nele se joga, das coisas materiais e simbólicas em jogo que nele se geram" (BOURDIEU, 1989, p. 69). Dessa maneira, podemos afimar que há um ritual, uma porta de entrada no campo acadêmico distinto e que a IC é uma dessas formas. É condição para os iniciantes a disposição para aprender a jogar o jogo e aceitar as regras do jogo de pertencimento à Instituição na condição de bolsista. Assim sendo, materializar a IC "é adentrar um espaço habitado por professores, pesquisadores e demais alunos e seguir uma determinada etiqueta que poderá formá-lo como um pesquisador no futuro, é começar seu processo de formação em pesquisa" (SCORSOLINI-COMIN, 2014, p. 2), pois não se nasce pronto para pesquisar (NEVES; LEITE, 2002).

Essa mobilização para entrar no campo advém dos efeitos materiais e simbólicos propiciados pela incorporação do bolsista de IC no campo. No caso do campo acadêmico esses efeitos materializam-se no status, no capital social e educacional que pode ser aquirido com a constituição do bolsista como pesquisador, mesmo que iniciante, com alguns efeitos positivos também em relação ao capital econômico, pois não se pode desconsiderar que, embora constituindo um valor irrisório, a bolsa é um poderoso chamariz.

\section{QUESTIONAMENTOS QUE SE IMPÕEM}

Frente ao acima exposto e retomando nossa temática, questionamos: como se situam os universitários que passam a compor o ainda restrito grupo daqueles que tiveram ou conquistaram a possibilidade de participarem da Iniciação científica ou de adentrarem a este campo acadêmico? Quais são as marcas, os signos visíveis da formação e transformação da sua nova identidade como universitários que participam da IC: O exíguo valor da bolsa que

\begin{tabular}{l|c|c|c|c|c|c} 
() Rev. Educ. Perspec. & Viçosa, $M G$ & v.8 & n.1 & p.124-140 & jan./abr. 2017 & eISSN 2178-8359 \\
\hline
\end{tabular}


recebem no final do mês? ${ }^{v}$ A participação em grupos de pesquisa? A iniciação em um relacionamento diferenciado com um professor/pesquisador, na condição de orientando? $\mathrm{O}$ desafio de aprofundar uma temática, sistematizar, escrever e publicizar suas descobertas em eventos de IC? As recompensas materiais (bolsa) e simbólicas (status)? A visualização de ter mais chances de acessar o mestrado?

E mais: Os participantes da IC conseguem aperceber-se do fato de que, bourdieanamente falando, a sua nova identidade os coloca na condição de "distinção" (BOURDIEU, 2008) frente aos "de fora"? Como aproveitam esta oportunidade? Como se defrontam com este desafio? Demonstram aperceber-se que esta chance traz inoculada uma nova e desafiadora responsabilidade? Que relações de poder atravessam essa "zona de desenvolvimento proximal" (VIGOTSKY, 1984) entre o orientador e o aluno que adentra o campo da IC? Com que empecilhos precisam defrontar-se os discentes ou que facilidades lhes são proporcionadas para que incorporem o novo habitus próprio da IC? A afirmação e a ampliação da IC - abrangendo agora também alunos da EB - significa uma forma de dizer que a docência que professamos e a pesquisa que fazemos estão no caminho certo e que precisam continuar? Como orientadores e discentes estão vivenciando essa fase de indeterminação, ou parafraseando Rodolpho (2004, p. 142), essa condição dos alunos de IC que "não são mais o que eram, mas também ainda não são o que deles se espera", ao serem concluídos os rituais da iniciação? Que experiências, que registros, que pesquisas existem a respeito desta praxis que visa a construção de um docente mais autônomo, de um pesquisador mais qualificado? Como orientadores e bolsistas de IC podem convergir no sentido de que o processo no qual estão envolvidos converta-se em um "círculo virtuoso" (CURY, 2004) do qual resultem benefícios individuais e coletivos?

Há evidências de que esta relação pode estar atravessada pela informalidade e precariedade, no sentido de que o discente, na condição de pesquisador iniciante, esteja sendo obrigado a cobrir espaços ou cumprir tarefas que, de fato e de direito, deveriam ser exercidas por funcionários da universidade? Enfim, em que medida o ritual da IC se aproxima e/ou particulariza-se na relação com os clássicos rituais de iniciação/passagem?

Estes são questionamentos que, certamente, nos limites de um artigo, não podem ser equacionados. Porém as leituras e pesquisa que fizemos nos autorizam a realçá-los no sentido de transformar a IC em uma praxis, de tal forma que os nela envolvidos, além de executá-la, preocupem-se com o salto de qualidade ou na sua transformação em um círculo virtuoso, a fim de que a qualificação dessa relação repercuta na elevação da qualidade da educação intra e entre níveis de ensino institucional. A IC carrega o potencial de instaurar uma nova relação entre ensino e pesquisa, entre docentes e discentes. 


\section{A INICIAÇÃo CIENTífICA COMO TEMÁtICA DE DEBATE E PESQUISA}

Em nossa manifestação sobre a temática, estamos referindo-nos a um 'assunto-criança' se pensarmos na quase milenar história da universidade: a institucionalização de uma política pública, a IC. Porém, embora seja um 'tema-criança' - dado que a primeira Resolução que o normatiza é de 1993 - já conta com uma história digna de anais e mobilizadora de Encontros Institucionais. De uma prática inicialmente errática, pouco sistematizada, fruto de iniciativas isoladas, passa-se à sua institucionalização por meio de Resoluções Normativas (RN) ${ }^{\mathrm{vi}}$. Como decorrência de sua institucionalização, originam-se cada vez mais numerosos e amplos Seminários nos quais o processo e os resultados da IC são socializados e debatidos. Complementarmente transforma-se em temáticas de livros e coletâneas, como, dentre outros os de: Marcuschi (1996); Aragón (1999); Calazans (2002); Ferreira (2003); Ferreira et al (2010); Scorsolini-Comin (2014); Carrara (2014). Nesse trajeto a IC passa, também, gradativamente a transformar-se em tema de pesquisa, dando origem a dissertações, teses e artigos decorrentes destas, como: Filipecki, Barros, Elia (2006); Pires (2008); Silva (2012), entre outros. Em outras palavras, poderíamos afirmar que de uma prática instituída, passou a ser instituinte, transformando-se numa espécie de modelo para outras iniciativas similares, extrapolando até o próprio locus inicial, a graduação, migrando à EB, originando a institucionalização da ICJ no ano de 2003.

De outra parte seus idealizadores - do CNPq desde a origem e da CAPES, mais recentemente - projetaram e induziram estratégias de garantir que a passagem pela IC instrumentalizasse o discente da graduação a estar mais preparado para o leque de questões que envolve o fazer pesquisa, de tal forma que este estivesse mais preparado para ingressar na pós-graduação (PG) e, como numa espécie de queima de etapas, tivesse vantagens comparativas com outros pós-graduandos e assim conseguisse reduzir o seu tempo médio de titulação (TMT), contribuindo com a melhora dos rankings de Programas de PG e das próprias IES e órgãos governamentais. De um lado, sobressai-se aqui uma perspectiva pragmática e utilitária a ser levada em conta e debatida. Nesse contexto utilitarista muitos orientadores manifestam preferências por assumir, como orientandos, os 'Iniciados' na pesquisa, os que já incorporaram o habitus, como afirmam Kuenzer e Moraes (2009, p. 188):

(...) de modo preferencial os que trazem experiência de bolsas de IC - com suficiente autonomia intelectual para dominar as categorias teórico-metodológicas em um ano, e com condições para finalizar a "pesquisa" ao final do segundo ano, admitida uma extensão de mais seis meses de prazo para os não bolsistas.

Por outro lado - o da qualificação que o discente da graduação, via IC, possa construir na passagem pelo processo -, criam-se as condições para aquilo que, como já apontamos, Cury

\begin{tabular}{l|l|l|l|l|l|l} 
(ㅇ) Rev. Educ. Perspec. & Viçosa, $M G$ & v.8 & n.1 & p.124-140 & jan./abr. 2017 & eISSN 2178-8359 \\
\hline
\end{tabular}


(2004) denomina de "círculo virtuoso" entre graduação e PG. Assim, a IC vista sob este último aspecto, do seu surgimento na graduação expande-se para a EB e se projeta em seus efeitos para a PG, agregando aspectos que permitem falar-se em "sistema educacional".

\section{DA INEXISTÊNCIA À CONDIÇÃO DE 'PRIMA RICA' OU DA MONITORIA À ICJ}

A partir do Parecer $n^{\circ}$ 977/65 e do Parecer $n^{\circ} 77 / 69$, no Brasil foi criada uma PG que primeiro era para "formar professores", depois passou a priorizar a "formação de pesquisadores". Nesta perspectiva é que precisamos entender o primeiro movimento de transformar alguém em um professor universitário, isto é, a Iniciação à Docência que tem na monitoria o seu locus espácio-temporal privilegiado. Conforme palavras de uma ex-pró-reitora de graduação da Universidade Federal de Santa Catarina, em seu depoimento a Steinbach (2015), nos anos de 1970, a monitoria era "uma preparação para a docência", "para formar futuros docentes". Este, poderíamos dizer, foi um dos primeiros e mais consistentes movimentos para a construção da "profissionalidade docente" (BAZZO, 2007).

Na medida em que a PG stricto sensu se expande, a "formação de pesquisadores" adquire a primazia e a "formação de professores" passa a ser secundada. E como a construção de uma cultura científica é um processo demorado, a monitoria continua existindo, porém o que dá retornos materiais e simbólicos, o que distingue é ser pesquisador. E, para tanto, constituemse estratégias, da parte do discente, para ser admitido na IC e por parte dos docentesorientadores de reprodução do campo acadêmico, com foco na investigação.

No afã de constituição e afirmação desse novo campo, os bolsistas de IC muitas vezes, a despeito do prescrito nas Resoluções Normativas, são mobilizados a práticas diferentes daquelas que deveriam exercer na graduação (CALAZANS, 2002). Além disso, quando da sua inserção na EB, uma vez que ainda predomina uma educação com características bancárias (FREIRE, 2011), onde o professor dá o conteúdo e o aluno devolve/repete, acaba por criarem-se dificuldades ou impedimentos na almejada constituição do pensamento crítico. Com isto retarda-se ou, no limite, impede-se a implementação de uma praxis mobilizada no processo de IC que implica não somente "aprender a coletar e analisar dados, mas questionar permanentemente o sentido de ser pesquisador, a relevância social do que é pesquisado e o dialógico com outras pesquisas, com o conhecimento já produzido, com as pessoas e as comunidades" (SCORSOLINI-COMIN, 2014, p.7).

Entretanto, como afirmamos anteriormente, a institucionalização da IC tem criado possibilidades de qualificar a relação entre a PG stricto sensu e a graduação, principalmente nas IES públicas, consubstanciando um "círculo virtuoso em que as especificidades de cada

\begin{tabular}{l|c|c|c|c|c|c} 
(C) Rev. Educ. Perspec. & Viçosa, $M G$ & v.8 & n.1 & p.124-140 & jan./abr. 2017 & eISSN 2178-8359 \\
\hline
\end{tabular}


qual se beneficiem mutuamente" (CURY, 2004, p. 779). Além disto, favorece a materialização da relação ensino e pesquisa e a tendência de beneficiar o discente por ter participado da IC nas seleções para o mestrado e doutorado. Embora Saviani (2012) levante dúvidas, a partir das condições existentes, a respeito de absolutizar a transformação da IC em um antepasso para a PG stricto sensu.

Nesse contexto, em 2012, a CAPES lança o Programa Bolsas Jovens Talentos para a Ciência (PJT-IC) com o objetivo de "preparar os estudantes para" o Programa Institucional de Iniciação à Docência (PIBID), o PIBIC e o Programa Ciência Sem Fronteiras (CAPES, 2014). No lançamento do PJT-IC os presidentes da CAPES e do CNPq declaram a importância da inserção o mais cedo possível, dos discentes, no campo acadêmico (NOVAIS, 2012). Assim, com a criação desses Programas antecipam de certa forma a ICJ para as fases iniciais da graduação, bem como a estendem à EB e a reconhecem como um dos meios de qualificação quer para a entrada na PG, quanto para o próprio desempenho do discente na ES, seja na qualidade da pesquisa, seja na redução do tempo para conclusão do mestrado e doutorado.

\section{OS DESAFIOS E LIMITES DA INSERÇÃO DOS BOLSISTAS DE ICJ NO CAMPO ACADÊMICO}

Não há como negar, apesar do caráter indutivo, o sucesso dessa política pública a partir das articulações do $\mathrm{CNPq}$ com as universidades e agências estaduais de fomento à pesquisa (FAPs), uma vez que é condição do financiamento a apresentação de contrapartidas em relação aos investimentos em bolsas de IC. Esse processo de constituição e implementação dessa política permite dizer que a IC é uma das políticas de estado com ramificações na EB, na graduação e na PG, via CNPq, CAPES, FAPs e nas IES. Mas, se temos muito a festejar em relação ao muito que foi conseguido em tão pouco tempo, falando em perspectiva histórica, não podemos sucumbir ou deixar que questões preocupantes, obnubilem o fato de que continuamos com inúmeros problemas relacionados ao quanto ainda estamos mais próximos de uma prática, com suas contradições, muitas vezes empobrecedoras ou até imobilizadoras da IC, do que de uma praxis, na qual as contradições são o motor para a superação de situações inaceitáveis, seja de origem, sejam de processo, sejam de resultados.

Um dos aspectos a ser colocado em relevo relaciona-se à precarização que envolve a condição do aluno de iniciante à pesquisa à categoria de 'trabalhador' precário. Aqui entram questões relacionadas ao desvio ou ao gap entre o que é concebido como o ideal da ICJ e aquilo que efetivamente acontece no processo. Uma das dificuldades do bolsista iniciante é a

n.1 1 p.124-140

\begin{tabular}{l|l} 
jan./abr. 2017 & eISSN 2178-8359
\end{tabular}


familiarização com a dinâmica de funcionamento do campo acadêmico, relacionada principalmente ao conhecimento do campus, aos contatos, as exigências administrativas como a elaboração do currículo Lattes e, até, de abrir conta em banco. Porém as dificuldades maiores dos bolsistas estão relacionadas: ao processo de elaboração do projeto e sua execução; análise dos dados; articulação teórico-metodológica; escrita de relatórios e artigos; preocupação com a forma (ABNT); e submeter à pesquisa ao comitê de ética. Isto é, no conjunto ele precisa construir um novo habitus, um novo modo de ser. Esses obstáculos epistemológicos/teóricos/metodológicos são assinalados por Oliveira (2011, p. 302) e por Carrara (2014, p. 20), respectivamente, quando ressaltam as dificuldades dos bolsistas "em efetuar a relação entre a teoria e a prática" e a explicitação "do contexto filosóficoepistemológico em que se fundam as interpretações desses dados”.

Além desses empecilhos no que diz respeito ao trabalho, há também as questões relacionadas ao poder dos professores orientadores sobre os bolsistas, porque esses estão "mais bem posicionados" (VALLE, 2013, p. 417), explicitando uma relação desigual entre os segmentos, seja na PG, na graduação e de forma mais gritante na EB. Essas situações manifestam-se, por exemplo, quando há alguma apropriação do trabalho por parte dos seus orientadores, particularmente nos casos em que a intervenção sobre os textos acaba sendo nula ou mínima e nos momentos em que os bolsistas são induzidos a realizar a coleta de dados à pesquisa do orientador. Essa forma heterônoma de estabelecimento da relação orientador-orientando é favorecida/induzida pela política de avaliação e financiamento da CAPES (BIANCHETTI, 2012) direcionada, por exemplo, para a redução do TMT.

Muitas dessas dificuldades dos orientadores da ICJ e/ou da PG stricto sensu advêm da precária formação para exercer essa função, como constatado por Bianchetti (2014), em seu projeto de pesquisa subsidiado pelo CNPq. Não é suficiente para ser um bom orientador, ser doutor e ter ampla experiência em pesquisa, porque as relações cognitivas, afetivas e atitudinais implicadas no processo de formação de um pesquisador exige domínio didáticocientífico desse processo, levando-nos a afirmar a necessidade das universidades estabelecerem espaços/tempos de formação do orientador. Em síntese, não é pelo fato de alguém ter sido orientado que, ipso facto se transforma em um orientador. Contrariamente a isto, além das frustrantes experiências de orientadores iniciantes, há obras, como a de Walker e Thomson (2010), que compreendem e explicitam a necessidade de que a orientação seja concebida como uma "Pedagogia" que pode ser ensinada e aprendida, apregoando assim a necessidade de uma "didática" da orientação.

Alguns estudos sobre esse processo indicam pistas de como o orientador pode desencadear as mediações com o orientando de maneira a qualificar a formação do pesquisador e contribuir para a produção do conhecimento. Viana e Veiga (2010) destacam atitudes como: valorizar o

\begin{tabular}{l|c|c|c|c|c|c} 
() Rev. Educ. Perspec. & Viçosa, $M G$ & v.8 & n.1 & p.124-140 & jan./abr. 2017 & eISSN 2178-8359 \\
\hline
\end{tabular}


diálogo; devolver os textos com comentários o mais rapidamente possível; manter-se sempre atualizado com os temas em estudo; prezar a convergência entre o seu objeto de pesquisa e do orientando; ajudar a delimitar o tema de pesquisa; respeitar os encontros agendados; ter tempo disponível para orientação individual e coletiva. A orientação coletiva por meio de grupos de pesquisa é indicada como um dos caminhos "do solitário ao solidário" (BIANCHETTI, 2014a), possibilitando o compartilhamento dos processos de produção do conhecimento e de formação do pesquisador.

No somatório, contudo, as virtudes da ICJ superam em muito os 'desvios' (OLIVEIRA, 2015). E em um tempo em que o "alongamento da escolarização é sinônimo de emprego" (MATTOS, 2011), o aluno de ICJ começa o seu 'treinamento' de lidar com a precarização desde cedo. De outro lado, porém, são muitas as possibilidades que se abrem para a instauração de um círculo virtuoso, de uma relação mais orgânica da graduação, com os graus que a antecedem (EB) e que a sucedem (PG). E dadas as condições cada vez mais exigentes do mercado de trabalho, certamente os estudantes que conquistam ou lhes é estendida esta possibilidade estarão mais 'apetrechados', melhorarão seu poder de barganha ao buscarem sair de situações de precariedade para acessar a postos de trabalho mais desafiadores e mais realizadores, do ponto de vista material (salário) e simbólico (status, realização).

Além disso, os saberes possibilitados pela participação na IC podem conduzir os bolsistas à aprendizagem de que "com o saber cresce a dúvida" (GOETHE, apud GIANNETTI, 2008), contribuindo para ferir de morte a nossa pretensão de que conhecemos. Assim, quando começamos a dar os primeiros passos na pesquisa, na descoberta, na formação, no conhecimento do mundo, mais percebemos o quão pouco sabemos, o quanto somos ignorantes (no sentido socrático de que ignoramos mais coisas do que sabemos). $\mathrm{O}$ reconhecimento da ignorância gera humildade e disposição para a busca, para a construção de conhecimentos, para agir nos atentados contra a ignorância, para exercemos a nossa condição de humanos, nos apropriando da nossa experiência histórico-social, conhecendo as "propriedades reais das coisas" (LUKÁCS, 1979, p. 19) e constituindo novas possibilidades de ser e estar no mundo. O desenvolvimento desses habitus, desse modo de ser, dessa "individualidade para si” (DUARTE, 2013) torna-se a condição para constituição do espírito científico, para formação do pesquisador e à produção do conhecimento. Dessa maneira, favorecendo a saída da "menoridade", por meio do cultivo de "seus próprios pensamentos" (KANT, 2003), estabelecendo processos autônomos.

No entanto, seria de se esperar da universidade, dos responsáveis pelo fomento e pela realização do processo de IC, algo que ultrapassasse essas questões próprias de um sistema no qual um investimento somente se realiza em plenitude caso haja retorno equivalente.

n.1 1 p.124-140




\section{CONSIDERAÇÕES FINAIS}

A despeito de a IC, particularmente a ICJ, ser uma política pública bastante recente, constatamos que sua implementação e expansão, com alguns momentos de estagnação ou retração em termos de financiamento - especialmente nas mudanças de governo ou em fases críticas e nas crises cíclicas do capital -, pode ser considerada uma política de sucesso por: possibilitar a articulação entres as agências de fomento, a universidade (graduação e PG) e a EB em torno do processo de escrita/pesquisa; favorecer a preparação para seguir a carreira acadêmica e de acesso a postos de trabalho; ser uma estratégia de muitos bolsistas de "galgar novas posições" rompendo com a sua posição social. Além disso, a IC pode ser considerada um ritual de passagem e de iniciação, pois desempenha um papel pedagógico e de formação, inserindo os jovens no habitus característico do campo acadêmico.

Devido à relevância da IC na formação de futuros pesquisadores, não temos dúvidas em afirmar: é uma iniciativa que para além de ser política de um governo, deveria cada vez mais afirmar-se como política de estado. O histórico da IC nos autoriza a concluir que as variações nas dotações orçamentárias, a estagnação por longos períodos no valor das bolsas pagas, os desvios a que está sujeita a prática da IC, ao arrepio dos objetivos proclamados ${ }^{\mathrm{vii}}$ são indícios de uma política que ainda demanda decisões mais concretas dos governantes no sentido de que estamos frente a uma prioridade.

Se de um lado podemos falar em política de sucesso, de outro, no entanto, paradoxalmente, constatamos que ainda há poucas investigações de fôlego que permitam assegurar, com base em dados, que esse sucesso se traduz em uma efetiva Iniciação à Pesquisa qualificada, em seu processo e resultados.

Se cada vez mais, por opção dos responsáveis pela avaliação e financiamento, em especial da PG, a primazia da pesquisa é afirmada; se com as cada vez mais disseminadas e potentes tecnologias digitais (TD), a pesquisa se impõe em relação ao ensino e à extensão, será que na prática podemos constatar e confirmar as máximas de dois grandes teóricos, segundo os quais: a) "há um tempo em que se ensina o que se sabe. Vem outro tempo porém em que se ensina o que não se sabe. Isto se chama pesquisa" (BARTHES, 1997, p. 47); b) invertendo-se o paradigma da supremacia do ensino, Marques (2011) eleva o "escrever a princípio da pesquisa". Frente a isto, podemos afirmar que está conseguindo-se passar do ensino da pesquisa, ao ensino pela pesquisa? O escrever tem sido elevado à condição de princípio da pesquisa ou conforme palavras de Marques (2011), segundo o qual "escrever é preciso", preconizando o primado da escrita? 
Pensamos que pesquisar, registrar/escrever e publicizar processos e resultados da ICJ compõem poderosos pilares e estruturas da metáfora do "circulo virtuoso" a que aludimos. Se estas duas frentes - a pesquisa e a escrita-publicização - não se constituíram ainda no ser/fazer da IC, dúvidas podem ser levantadas quanto ao alcance dos propalados objetivos dessa política pública.

Por fim, particularmente em relação à EB, a ICJ carrega o potencial de um pedagógico ritual de iniciação/passagem a outras etapas da escolarização institucional e das etapas e dos processos de formação pessoal e acadêmica.

\section{REFERÊNCIAS}

ARAGÓN, Virgílio. (Coord.) O Programa institucional de bolsas de iniciação científica (PIBIC) e a sua relação com a formação de cientistas. Relatório Final. Brasília: UnB/ NESUB, 1999.

BARTHES, Roland. A aula. 7 ed. São Paulo: Cultrix, 1997.

BAZZO, Vera Lúcia. Constituição da profissionalidade docente na educação superior: desafios e possibilidades. 2007. 265f. Tese (doutorado) - Faculdade de Educação. Universidade Federal do Rio Grande do Sul, Porto Alegre.

BIANCHETTI, Lucídio; MACHADO, Ana Maria N. Orientação/escrita de dissertações e teses em questão: produção científica e estratégias de orientadores e Coordenadores de PPGEs. Relatório final de projeto do CNPq, Edital Universal (Processo 479166/01-3). Florianópolis, PPGE/UFSC, 2005.

BIANCHETTI, Lucídio. O desafio de escrever dissertações/teses: como incrementar a quantidade e manter a qualidade com menos tempo e menos recursos? In: BIANCHETTI, Lucídio; MACHADO, A. M. N. (Org.). A bússola do escrever: desafios e estratégias na orientação e escrita de teses e dissertações. 3 ed. São Paulo: Cortez, 2012.

BIANCHETTI, Lucídio. Formação e atuação de orientadores de dissertações e teses: De uma prática intuitivo-individual à uma práxis coletivo-grupal em vias de formalização/afirmação. Em direção a uma 'pedagogia' da orientação. 2014. Projeto de pesquisa encaminhado ao CNPq, para ser desenvolvido entre 2015 a 2019, na condição de Pesquisador Produtividade.

BIANCHETTI, Lucídio. Do solitário ao solidário. Relato e reflexões sobre uma praxis em um Programa de Pós-Graduação em Educação. In: OLIVEIRA, Adriano de; ARAUJO, Emília Rodrigues; BIANCHETTI, Lucídio (Org.). Formação do investigador: Reflexões em torno da escrita/pesquisa/autoria e orientação. 1. ed. Braga, Portugal:

\begin{tabular}{l|c|c|c|c|c|c|} 
(C) Rev. Educ. Perspec. & Viçosa, $M G$ & v.8 & n.1 & p.124-140 & jan./abr. 2017 & eISSN 2178-8359 \\
\hline
\end{tabular}


CECS/UMINHO/CED/UFSC, PT, 2014a. v. 1. p. 74-93. Disponível em:

〈http://www.lasics.uminho.pt/ojs/index.php/cecs_ebooks/issue/view/151 >. Acesso em: 04 mar. 2017.

BOURDIEU, Pierre. A distinção. Crítica social do julgamento. Porto Alegre/São Paulo: Zouk /EDUSP, 2008.

BOURDIEU, Pierre. Os ritos de instituição. In: BOURDIEU, Pierre. A economia das trocas linguísticas: o que falar quer dizer. São Paulo: EDUSP, 1998, p. 97-106.

BOURDIEU. Pierre. O poder simbólico. Lisboa: Difel, 1989.

CALAZANS, Maria Julieta Costa. (Org.). Iniciação científica: construindo o pensamento crítico. São Paulo: Cortez, 2002.

CAPES. Programa Jovens Talento para Ciência. Edital n. 26/2014. Disponível em: <http://www.capes.gov.br/images/stories/download/editais/Edital_026_2014_JTC.pdf $>$. Acesso em: 17 nov. 2014.

CARRARA, Kester. Iniciação científica: um roteiro comentado para estudantes. São Paulo: Avercamp, 2014.

CNPq. Bolsas e taxas no país. 2013. Disponível em: <http://www.cnpq.br/web/guest/nopais>. Acesso em: 17 nov. 2015.

CURY, Carlos Roberto Jamil. Graduação/pós-graduação: a busca de uma relação virtuosa. Educação \& Sociedade, Campinas: CEDES, v. 25, n. 88, p. 777-794, out. 2004. Edição Especial.

DUARTE, Newton. A Individualidade para si: contribuição a uma teoria histórico-crítica da formação do indivíduo. 3.ed. Campinas: Autores Associados, 2013.

FERREIRA, Cristina Araripe. Concepções de iniciação científica no ensino médio: uma proposta de pesquisa. Trabalho, Educação e Saúde, v. 1, n. 1, p. 115-130, 2003. Disponível em: <http://www.epsjv.fiocruz.br/upload/ArtCient/10.pdf>. Acesso em: 04 abr. de 2017.

FERREIRA, Cristina Araripe; et al (Orgs.). Juventude e iniciação científica: políticas públicas para o ensino médio. Rio de Janeiro: EPSJV, UFRJ, 2010, p. 11-25.

FILIPECKI, Ana; BARROS, Susana de Sousa; ELIA, Marcos da Fonseca. A visão dos pesquisadores-orientadores de um programa de vocação científica sobre a iniciação científica de estudantes de ensino médio. Ciência e Educação, Bauru, v. 12, n. 2, p. 199-217, 2006.

FREIRE, Paulo. Pedagogia do oprimido. 50 ed. Rio de Janeiro: Paz e Terra, 2011.

\begin{tabular}{l|c|c|c|c|c|c|} 
(C) Rev. Educ. Perspec. & Viçosa, $M G$ & v.8 & n.1 & p.124-140 & jan./abr. 2017 & eISSN 2178-8359 \\
\hline
\end{tabular}


GIANETTI, Eduardo. O livro das citações. São Paulo: Companhia das letras, 2008.

KANT, Immanuel. O que é o esclarecimento? Revista Espaço Acadêmico, Rio de Janeiro, n. 31, dez. 2003. Disponível em: 〈http://www.espacoacademico.com.br/031/31tc kant.htm>. Acesso em: 31 mar. 2017.

KUENZER, Acácia Zeneida; MORAES, Maria Célia Marcondes de. Temas e tramas na pósgraduação em educação. In: BIANCHETTI, Lucídio; SGUISSARDI, Valdemar. (Orgs.). Dilemas da Pós-graduação. Campinas: Autores Associados, 2009.

LUKÁCS, György. Questões Metodológicas Preliminares. In: Ontologia do ser social: os princípios fundamentais de Marx. São Paulo: Editora Ciências Humanas, 1979. p. 11-34.

MARCUSCHI, Luiz Antônio. Avaliação do Programa Institucional de Bolsas de Iniciação Científica (PIBIC) do CNPq e Propostas de Ação. Recife: URPE, 1996. MARQUES, Mario Osório. Escrever é preciso. O princípio da pesquisa. 2 ed. Petrópolis: Vozes, 2011.

MATTOS, Valéria de Bettio. Pós-graduação em tempos de precarização do trabalho: alongamento da escolaridade e alternativa ao desemprego. São Paulo: Xamã, 2011.

NEVES, Rosa Maria das; LEITE, Siomara Borba. A iniciação científica: vocação de genialidades ou prática cultural? In: CALAZANS, Maria Julieta C. (Org.). Iniciação científica: construindo o pensamento crítico. São Paulo: Cortez, 2002, p. 163-183.

NOVAIS, Gisele. Jovens talentos: novo programa pretende inserir estudantes no meio científico. 2012. Disponível em: http://portal.mec.gov.br/index.php?option=com content\&view=article\&id=17562: novo-programa-pretende-inserir-estudantes-no-meiocientifico\&catid=209. Acesso em: 28 fev. 2017.

OLIVEIRA, Adriano de. A Iniciação Científica Júnior (ICJ): aproximações da educação superior com a educação básica. Tese (Doutorado) - Centro de Ciências da Educação, Universidade Federal de Santa Catarina, Florianópolis, 2015.

OLIVEIRA, Ivanilde Apoluceno. Projetos de iniciação científica no campo educacional. In: BIANCHETTI, Lucídio.; MEKSENAS, Paulo. (Orgs.). A trama do conhecimento. Teoria, método e escrita em ciências e pesquisa. 2 ed. Campinas: Papirus, 2011.

PIRES, Regina Celi Machado. A formação inicial do professor pesquisador universitário no Programa Institucional de Bolsas de Iniciação Científica - PIBIC/CNPq e a prática profissional de seus egressos: Um estudo de caso na Universidade do Estado da Bahia. 2008. 356f. Tese (doutorado) - Faculdade de Educação, Universidade Federal do Rio Grande do Sul, Porto Alegre. 
RODOLPHO, Adriane Luisa. Rituais, ritos de passagem e de iniciação: uma revisão da bibliografia antropológica. Estudos Teológicos, São Leopoldo, EST, v. 42, n. 2, p. 138-146, 2004.

SAVIANI, Demerval. A pós-graduação em educação no Brasil: pensando o problema da orientação. In: BIANCHETTI, Lucídio; MACHADO, Ana Maria Netto (Orgs.). A bússola do escrever. Desafios e estratégias na orientação e escrita de teses e dissertações. 3 ed., São Paulo: Cortez, 2012.

SCORSOLINI-COMIN, Fabio. Guia de orientação para iniciação científica. São Paulo: Atlas, 2014.

SILVA, Evellyn Ledur da. A universidade e o ensino da pesquisa: o caso do PIBIC da UFSC. Florianópolis. 2012. 146f. Dissertação (mestrado) - Centro de Ciências da Educação. Universidade Federal de Santa Catarina, Florianópolis.

STEINBACH, Greicy. A monitoria no ensino superior: um estudo de caso na UFSC. 2015. 176f. Dissertação (mestrado) - Centro de Ciências da Educação. Universidade Federal de Santa Catarina, Florianópolis.

VALLE, Ione Ribeiro. O lugar da educação (escolar) na sociologia de Pierre Bourdieu. Revista Diálogo Educacional, Curitiba, v. 13, n. 38, p. 411-437, jan/abr. 2013.

VAN GENNEP, Arnold. Os ritos de passagem. Petrópolis: Vozes, 1978.

VIANA, Cleide Maria Quevedo Quixadá; VEIGA, Ilma Passos Alencastro. O diálogo acadêmico entre orientadores e orientandos. Educação, Porto Alegre, v. 33, n. 3, p. 222-226, set/dez. 2010. Disponível em: <http://revistaseletronicas.pucrs.br/ojs/index.php/faced/ article/view/8079>. Acesso em: 17 mar. 2017.

VIGOTSKY, Lev Semyonovich. A Formação Social da Mente. São Paulo: Martins Fontes, 1984.

WALKER, Melanie; THOMSON, Pat. (Ed.). The routledge doctoral supervisor's companion. supporting effective research in education and the social sciences. London and New York: Toutledge, 2010. 


\begin{abstract}
'Adriano de Oliveira - Coordenador Pedagógico na Rede Municipal de Ensino de Florianópolis. Mestre e Doutor em Educação pela Universidade Federal de Santa Catarina. Estágio doutoral no ICS/Universidade do Minho. E-mail: adriano.deoliveira2@gmail.com

ii Lucídio Bianchetti - Professor aposentado/voluntário na Universidade Federal de Santa Catarina. Mestre e Doutor em Educação pela PUC-Rio. Estágio Pós-doutoral na Universidade de Porto. E-mail: lucidiob@gmail.com
\end{abstract}

\title{
NOTAS
}

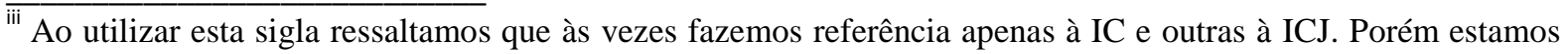
sempre referindo-nos a esse processo de iniciação do discente da graduação, da EB e/ou de ambos, na perspectiva de inserirem-se no processo de investigação.

iv Nas poucas vezes que citamos alguma manifestação destes, para garantir o anonimato, foram criadas siglas para representá-los, começando com "B01” (Bolsista n. 01) até o "B27”.

${ }^{v} \mathrm{O}$ valor atual das bolsas da IC na graduação é R \$400,00 e da ICJ é R \$100,00 (CNPq, 2013).

${ }^{\text {vi }}$ As RNs são as estratégias jurídico-legais utilizadas pelo CNPq, para a organização e o funcionamento da IC nas universidades. Até o momento foram publicadas oito (08) RNs. A $1^{\text {a }}$ do PIBIC foi a RN/05/1993. Para mais detalhes ver o site do CNPq e a pesquisa de Silva (2012).

vii Referimo-nos, entre outros, ao fato de alunos cumprirem tarefas informais e precarizadas que são estranhas ao leque de atribuições inerentes à IC de acordo com as normas do CNPq.
}

Submetido em: 03-12-2015 - Aceito em: 01-09-2016.

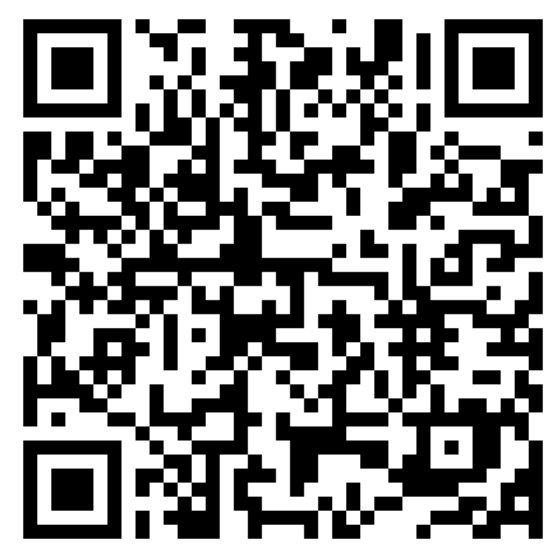

